\title{
Multicentric morphometric study of sexual dimorphism in body of first sacral vertebra of dry human sacra in Central India region
}

\author{
Deepak Sharma ${ }^{1}$, Sonia S Baweja ${ }^{2, *}$, Vandana A Sharma ${ }^{3}$ \\ ${ }^{1}$ Demonstrator, ${ }^{\mathbf{2}, 3}$ Associate Professor, Dept. of Anatomy, Gandhi Medical College, Bhopal, Madhya Pradesh, India
}

*Corresponding Author:

Email: soniabaweja14@gmsil.com

Received: $09^{\text {th }}$ February, 2018

Accepted: $23^{\text {rd }}$ February, 2018

\begin{abstract}
Human skeleton and its remains are important material for racial, genetic, anthropological and forensic investigations. Sacrum being the last skeletal remains proves important in sex determination \& identification of deceased. The first sacral vertebra is last to decay in the sacrum. This study is to validate the selected morphometric parameterss and indices related to first sacral vertebra and thus sex determination by the available part of human sacrum.

Multicentric study on 282 dry human sacra in central india region was conducted after due permission of institution ethics committee. Transverse, anterio-poeterior diameter of S-1 was measured and Index of S-1 was calculated.

Mean value of transverse diameter of first sacral vertebra is 4.78 and 4.46 and Anterio-posterio diameter is 3.07 and 2.89 for male and female sacra with t-value of 4.8839 and 4.2262 respectively \& P-value highly significant. Mean value for Index of S-1 for male and female is 8.4429 and 8.9327 respectively with t-value 0.0568 .

This multicentric study provides morphometric values of first sacral vertebra that can be used for determination of sex and forensic identification in Central India region. Morphometric indicators of first sacral vertebra can be used for the anatomical and forensic purpose where partial or broken sacra is only skeletal remains.
\end{abstract}

Keywords: First sacral vertebra, S-1, Sacrum, Identification point, Demarking point.

\section{Introduction}

Human sacrum is a large triangular bone formed by fusion of five sacral vertebra along with the intervening intervertebral discs and forms the caudal end of the vertebral column. It forms posterosuperior wall of the pelvic cavity wedged between two innominate bones. ${ }^{1}$

Anatomists, anthropologists and forensic experts judge the sex by non metric observations of the different bones available that is later confirmed by actual measurements of different bones. Earlier researchers like Pearson, Fisher, Stewart and Krogman studied the accuracy of sex identification on basis of study of individual bones. According to Krogman (1962) the degree of accuracy in sex identification on basis of complete skeleton was $100 \%$, pelvis with skull $98 \%$, pelvis alone $95 \%$, skull alone $90 \%$ and long bones alone $80 \%{ }^{2}$

Morphological features of bones depend on the nutritional, geographic, racial and occupational factors hence vary in different regions. Sacrum usually being last available skeletal remain, proves important in sexing and forensic identification. ${ }^{3}$ Many a times, only broken part of sacrum is available for forensic identification, especially in such case the base of sacrum remains intact but the apex is usually broken so the most reliable and widely used sacral index can not be measured.

Base is wider and articulates with fifth lumbar vertebra at lumbosacral angle. It is formed by the upper surface of S1. The body is large and wider transversely, its anterior projecting edge is the sacral promontory. The vertebral foramen is triangular, its pedicle being short and divergent posterolaterally. The laminae are oblique, directed posteromedially to meet at spinous tubercle. Superior articular processes are directed posteromedially to articulate with Inferior Articular Process of L5. Transverse process is a broad sloping mass that projects laterally from the body; pedicle and Superior articular Process are unique features of sacrum which are over shadow in L5. The transverse process and costal elements are fused together to the rest of the vertebra forming the superior part of the sacral lateral masss or ala. ${ }^{1}$

Bagde (1981) studied several parameters on the basis of metric measurements of 65 males and 30 female sacra from Marathwada region. The findings indicated that the length of the sacrum was the most suitable parameter followed by antero-posterior diameter and transverse diameter of the body of S1. The sacral and carporobasal index were less reliable than the other parameters. ${ }^{4}$

Vinod kumar et al (1984) studied 90 adult human sacra from Jhansi. The measurements consisted of sacral length and breadth, anteroposterior and transverse diameter of articular surfaces of the body of S1, length of sacral ala and sacral hiatus; they observed that the average length of left sacral ala was more in both the sexes than at ala. Also based on statistical tests, the sacral index was observed to be a more useful parameter in determining the sex. ${ }^{5}$ 
Mishra et al (2003) studied various measurements in Agra region on similar lines. Material for study consisted of 116 dry adult sacra (74 male sacra and 427 female sacra). It was found that demarking points of length of sacrum, auricular surface, sacral index and auricular index were most reliable in sexing the sacra. The study was said by the author concludes that not a single parameter could identify the sex of the sacrum with $100 \%$ accuracy. Hence for better results maximum number of parameters should be taken to attain $100 \%$ accuracy. ${ }^{6}$

Patel Zarana K et al (2011) studied 150 dry human sacrum of unknown sex to test the validity of morphometric parameters in Gujarat region. Sacral height straight ranges between 7 to $11 \mathrm{cms}$ whereas sacral width ranges between 7 to $11 \mathrm{cms}$. Transverse diameter of S-1 was between 3.1 to $5 \mathrm{cms}$, Anteroposterior length of body of S-1 was 1 to $3 \mathrm{cms}$, Maximum length of auricular surface is 3.1 to $5 \mathrm{cms}$, and maximum width of auricular surface is 1 to $3 \mathrm{cms}$ commonly. ${ }^{7}$

The first sacral vertebra will be the last to be available in decaying process for the purpose of forensic identification. In such cases, morphometry of $\mathrm{S}-1$ of sacrum can be done. Hence present study is an attempt to establish and validate selected sacral parameters of first sacral vertebra of sacrum for sex identification in central India region for anthropometric and forensic purpose.

\section{Materials and Methods}

Dry human Sacra of unknown sex are collected and studied from Department of Anatomy, Gandhi Medical College, Bhopal (M.P.), Department of Forensic medicine and Toxicology, Gandhi Medical College, Bhopal (M.P.), Regional Medicolegal Institute, Bhopal(M.P.), Department of Anatomy, NSCB Medical College, Jabalpur (M.P.), Department of Anatomy, SSMC, Rewa (M.P.), Department of Anatomy, Pt. J.N.M. Medical College, Raipur (C.G.), Department of Anatomy, CIMS, Bilaspur (C.G.), Department of Anatomy, Horizon Dental College, Bilaspur (C.G.) after due permission of institutional ethics committee.

All available completely ossified dry human sacra without any visible variation or damage at the base of sacra are taken for study purpose. Variant sacra and Sacra with visible loss of skeletal elements or broken S1 are excluded from the study. Sample size was calculated in the present study the sample size is 143 estimated based on precision. Due to scarcity of dry human sacra, all available dry human sacra at any centre, satisfying the inclusion and exclusion criteria are measured and recorded after due permission of HOD/ Incharge. A total of 282 dry human sacra were measured and recorded by using standardized instruments and procedure. Measurement is done on the intact parts of the normal bones. Each linear recording was taken at least to the nearest millimeter by using digital sliding vernier calipers, standardized flexible ribbon tape and divider

Measurements recorded are:

1. Transverse diameter of the first sacral body (TD-S1): It is the maximum transverse diameter of the first sacral body measured taking one point on each side of the lateral most point on the superior surface of the body. Instrument used- sliding caliper

2. Anteroposterior diameter of the body of first sacral body: (AP-S1) It is the maximum possible diameter of body of first sacral vertebra taking one point on the anterosuperior border and other on the posterosuperior border. Instrument used-sliding caliper

By using above observations the following indices were calculated:

\section{Index of body of S1 =}

$$
\text { TD-S1 }
$$

Non metric analysis of the data set is conducted to find the male and female sacra. K - mean Cluster analysis is used to find the male and female sacra group on 282 data set, for the measured parameters of transverse and anteroposterior diameter of first sacral vertebral body. After obtaining two groups from cluster analysis, significance of measured factors under study between them is done by using student t- test.

Identification point calculated for each measurement, it is above or below the maximum or minimum value of observation for the sacra of opposite gender. Calculated Range is mean \pm 3 S.D. Demarking point for each measurement is above or below the maximum or minimum value of calculated range for the sacra of opposite gender. Epi - info 7 is used to analyse the data. Microsoft excel and word is used to generate graphs, charts, figures and tables.

\section{Results}

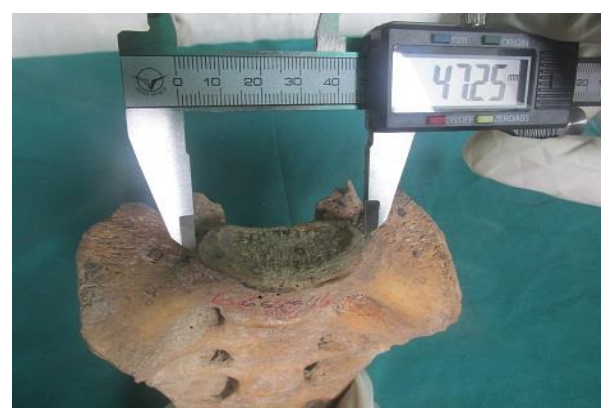

Fig. 1: T.D. of Ala 


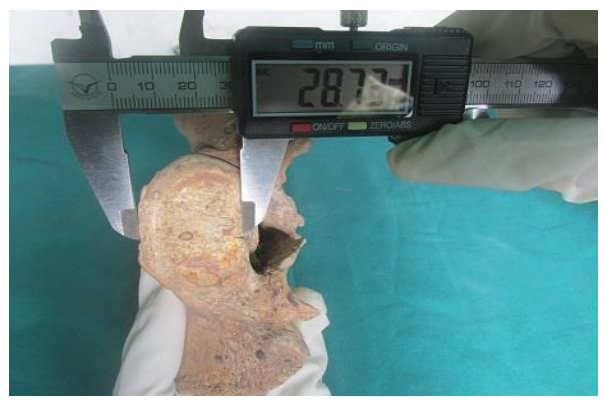

Fig. 2: A.P. of S-1

The results of the morphometric measurements of the first sacral vertebra are as follows:

Table 1: Anterior Posterior of S1 (cms)

\begin{tabular}{|l|c|c|}
\hline \multicolumn{1}{|c|}{ Detailed } & Male & Female \\
\hline $2.0-2.49$ & $2(1.4 \%)$ & $15(11.0)$ \\
\hline $2.5-2.99$ & $53(36.3 \%)$ & $65(47.8 \%)$ \\
\hline $3.0-3.49$ & $79(54.1 \%)$ & $51(37.5 \%)$ \\
\hline $3.5-3.99$ & $9(6.2 \%)$ & $5(3.7 \%)$ \\
\hline $4.0-4.49$ & $3(2.0 \%)$ & 0 \\
\hline Total No. of bones & 146 & 136 \\
\hline Range & $2.27-4.14$ & $2.24-3.97$ \\
\hline Mean & 3.0721 & 2.8904 \\
\hline Std. deviation & 0.3275 & 0.3275 \\
\hline Statistical significance & E.S. & E.S. \\
\hline Identification point & $>3.97$ & $<2.27$ \\
\hline Calculated range & $2.09-4.05$ & $1.83-3.95$ \\
\hline Demarking point & $>3.94$ & $<2.09$ \\
\hline Percentage beyond DP & $1.42 \%$ & 0 \\
\hline$\%$ of identified bones & $2.05 \%$ & $2.94 \%$ \\
\hline
\end{tabular}

$\mathrm{t}$ value $=4.2262, \mathrm{p}<0.0001$, Statistically extremely significant

Highest frequency of $79(54.1 \%)$ male sacra and $65(47.8 \%)$ of female sacra is in range of $3.0-3.49 \mathrm{cms}$ and $2.5-2.99 \mathrm{cms}$ respectively, showing divergence but next highest frequency of male $53(36.3 \%)$ and female sacra $51(37.5 \%)$ falls in the range of $2.5-$ $2.99 \mathrm{cms}$ and $3.0-3.49 \mathrm{cms}$ respectively showing considerable overlapping, whereas lower frequencies in male moves towards higher values and in females towards lower values. Mean values for male sacra are 3.07 and for female sacra is $2.89 \mathrm{cms}$ respectively.

Chart 1: Frequency Distribution of AnterioPosterior (A.P.) Diameter of S-1

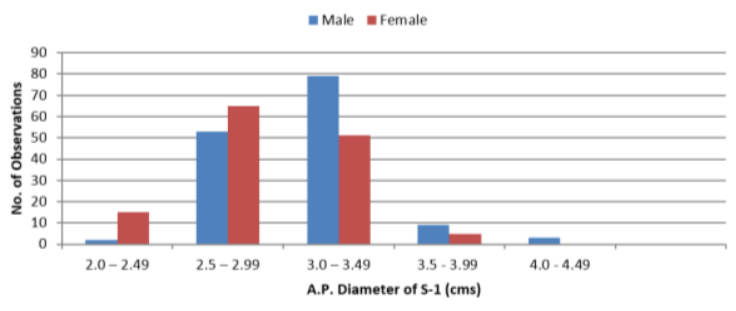

Table 2: Transverse Diameter (T.D.) of body of S1 (cms)

\begin{tabular}{|l|c|c|}
\hline Detailed Measurements & Male & Female \\
\hline $2.5-2.99$ & 0 & 0 \\
\hline $3.0-3.49$ & 0 & $6(4.4 \%)$ \\
\hline $3.5-3.99$ & $10(6.8 \%)$ & $21(15.4 \%)$ \\
\hline $4.0-4.49$ & $30(20.5 \%)$ & $37(27.2 \%)$ \\
\hline $4.5-4.99$ & $53(36.3 \%)$ & $48(35.3 \%)$ \\
\hline $5.0-5.49$ & $39(26.7 \%)$ & $22(16.2 \%)$ \\
\hline $5.5-5.99$ & $12(8.2 \%)$ & $2(1.5 \%)$ \\
\hline $6.0-6.49$ & $2(1.4 \%)$ & 0 \\
\hline Total No. of bones & 146 & 136 \\
\hline Range & $3.5-6.17$ & $3.11-5.59$ \\
\hline Mean & 4.7766 & 4.4582 \\
\hline Std. deviation & 0.5383 & 0.5425 \\
\hline Statistical significance & E.S. & E.S. \\
\hline Identification point & $>5.59$ & $<3.5$ \\
\hline Calculated range & $3.16-6.39$ & $2.83-6.08$ \\
\hline Demarking point & $>6.08$ & $<3.16$ \\
\hline Percentage beyond DP & $0.71 \%$ & $0.35 \%$ \\
\hline$\%$ of identified bones & $4.11 \%$ & $4.42 \%$ \\
\hline
\end{tabular}

t value $=4.8839, p<0.0001$, Statistically extremely significant

Highest frequency of $53(36.3 \%)$ of male sacra and $48(35.3 \%)$ of female sacra is in range of $4.5-4.99$ $\mathrm{cms}$, showing clustering in single range but second highest frequency of 39 (26.7\%) male sacra and 37 $(27.2 \%)$ female sacra falls in range of $5.0-5.49 \mathrm{cms}$ and $4.0-4.49 \mathrm{cms}$ respectively, showing considerable divergence.

Chart 2: Frequency Distribution of T.D. of Body of S-1

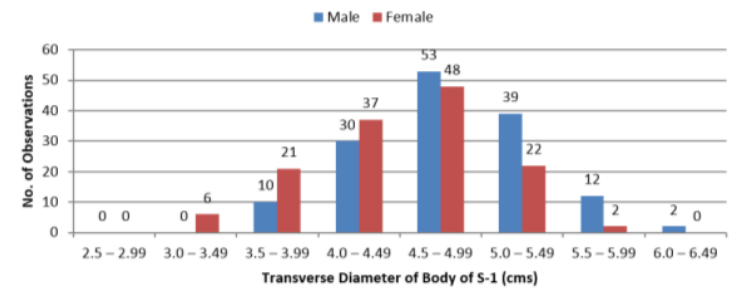

Table 3: Index of S1

\begin{tabular}{|l|c|c|}
\hline Derived Measurements & Male & Female \\
\hline $40-49.99$ & $1(0.7 \%)$ & $1(0.7 \%)$ \\
\hline $50-59.99$ & $39(26.7 \%)$ & $44(32.3 \%)$ \\
\hline $60-69.99$ & $73(50 \%)$ & $52(38.2 \%)$ \\
\hline $70-79.99$ & $27(18.5 \%)$ & $31(22.8 \%)$ \\
\hline $80-89.99$ & $3(2.05 \%)$ & $6(4.4 \%)$ \\
\hline $90-99.99$ & $3(2.05 \%)$ & $1(0.7 \%)$ \\
\hline $100-109.99$ & 0 & $1(0.7 \%)$ \\
\hline Total No. of bones & 146 & 136 \\
\hline Range & $47.76-97.62$ & $49.28-102.68$ \\
\hline
\end{tabular}




\begin{tabular}{|l|c|c|}
\hline Mean & 64.923 & 65.426 \\
\hline Std. deviation & 8.4429 & 8.9327 \\
\hline Statistical significance & N.S. & N.S. \\
\hline Identification point & $>102.68$ & $<47.76$ \\
\hline Calculated range & $39.97-89.76$ & $38.62-92.22$ \\
\hline Demarking point & $>92.22$ & $<39.97$ \\
\hline Percentage beyond DP & $0.71 \%$ & 0 \\
\hline$\%$ of identified bones & 0 & 0 \\
\hline
\end{tabular}

$\mathrm{t}$ value $=0.0568, \mathrm{p}=0.9548$, Statistically not significant

Mean values for male and female sacra are 64.923 and 65.426 with standard deviation of 8.4429 and 8.9327 respectively. Maximum frequency 73 (50.0\%) of male sacra and $52(38.2 \%)$ of female sacra falls in range $60-69.99$, followed by $27(18.5 \%)$ male sacra and $31(22.8 \%)$ female sacra in range $70-79.99$ respectively.

\section{Chart 3: Frequency Distribution of Index of S1}

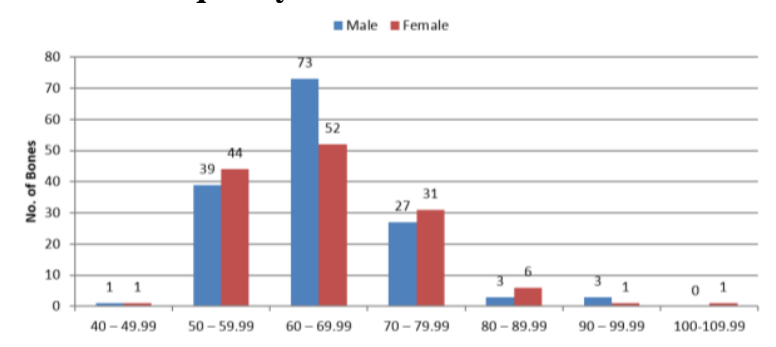

\section{Discussion}

Index of 51

In the present study, mean value for transverse diameter of body of $1^{\text {st }}$ sacral vertebra in males is $4.78 \mathrm{cms}$ and that for females is $4.46 \mathrm{cms}$. For male the demarking point is $>6.08$ and for female the demarking point is $<3.16 \mathrm{cms}$. Sacrum with transverse diameter of body of $1^{\text {st }}$ Sacral Vertebra measuring above $6.08 \mathrm{cms}$ is definitely a male sacra and below $3.16 \mathrm{cms}$ is definitely a female sacra.

Present findings nearly matched with those of Raju et al. (1980), kanika et al (2011), Mishra, S. R. et al. (2003 and Maddikunta V et al (2014). The mean T.D of $\mathrm{S} 1$ for male and female sacra in the present study is similar when compared to the values in the Australian aborigines. ${ }^{31}$ It is similar to north Indian population but slightly lower in comparison to Telangana and south Indian population. [Table -4]

Table 4: Comparison of present study with other studies for Transverse Diameter of Body of First Sacral Vertebra

\begin{tabular}{|c|c|c|c|c|c|c|c|c|c|}
\hline \multirow{2}{*}{\begin{tabular}{|l|} 
Previous \\
Researchers \\
\end{tabular}} & \multicolumn{4}{|c|}{ Male } & \multicolumn{4}{|c|}{ Female } & \multirow{2}{*}{\begin{tabular}{|l} 
S.S.D. \\
$P$ \\
\end{tabular}} \\
\hline & $\mathbf{N}$ & $\mathrm{x}$ & Range & S.D. & $\mathbf{N}$ & $\mathrm{x}$ & Range & S.D. & \\
\hline $\begin{array}{l}\text { Davivongs } \\
(1963)\end{array}$ & 50 & 4.74 & $3.6-5.3$ & 0.399 & 50 & 4.41 & $3.6-5.0$ & 0.368 & $<0.001$ \\
\hline \multicolumn{10}{|l|}{ Flander (1978) } \\
\hline White & 50 & 5.27 & - & 0.521 & 50 & 4.65 & - & 0.394 & $<0.01$ \\
\hline Black & 50 & 5.45 & - & 0.428 & 50 & 4.74 & - & 0.415 & $<0.01$ \\
\hline $\begin{array}{l}\text { Raju et al } \\
(1980)\end{array}$ & 33 & 4.73 & $\begin{array}{l}3.21- \\
6.26\end{array}$ & 0.509 & 11 & 4.21 & $3.56-4.86$ & 0.509 & $<0.01$ \\
\hline Bagde (1981) & 65 & 4.99 & $3.6-6.0$ & 0.520 & 30 & 4.34 & $3.15-5.10$ & 0.513 & $<0.001$ \\
\hline $\begin{array}{l}\text { S.S.Dapate } \\
(1997)\end{array}$ & 117 & 4.54 & $2.8-6.2$ & 0.615 & 83 & 4.01 & $2.7-5.5$ & 0.583 & $<0.05$ \\
\hline Mishra (2003) & 74 & 4.91 & $4.2-5.5$ & 0.327 & 42 & 4.28 & $4.0-5.0$ & 0.304 & \\
\hline Kanika S et al (2011) & 40 & 4.76 & $1.4-6.50$ & 0.71 & 10 & 4.55 & $3.9-5.50$ & 0.48 & 0.380 \\
\hline \begin{tabular}{|l|} 
Jyotinath K et al \\
$(2012)$
\end{tabular} & 45 & 4.46 & $3.4-5.5$ & 0.52 & 36 & 4.72 & $3.3-6.20$ & 0.71 & 0.0593 \\
\hline $\begin{array}{l}\text { Maddikunta V et } \\
\text { al(2014) }\end{array}$ & 27 & 4.87 & $3.82-5.84$ & 0.641 & 33 & 44.9 & $3.67-5.75$ & 0.572 & $<0.05$ \\
\hline Present Study & 146 & 4.78 & $3.5-6.17$ & 0.5383 & 136 & 4.46 & $3.11-5.59$ & 0.5425 & $<0.001$ \\
\hline
\end{tabular}

In the present study, the mean Antero-Posterior diameter of S-1 in male sacra observed in the present study is slightly in conformity with the Australian aborigines and Agra, Varanasi, North Indian studies as well as studies in Karnataka and Telangana region. The mean AP diameter of S1 in female sacra observed in the present study were 
high compared to the Australian aborigines and Agra region whereas it is similar to study in Amritsar, Punjab region. [Table-5]

Table 5: Comparison of present study with other studies for Antero-Posterior Diameter of Body of First Sacral Vertebra (S-1)

\begin{tabular}{|c|c|c|c|c|c|c|c|c|c|}
\hline \multirow{2}{*}{$\begin{array}{c}\text { Previous } \\
\text { Researchers }\end{array}$} & \multicolumn{4}{|c|}{ Male } & \multicolumn{4}{|c|}{ Female } & \multirow{2}{*}{\begin{tabular}{|c|} 
S.S.D. \\
P \\
\end{tabular}} \\
\hline & $\mathbf{N}$ & $\mathrm{x}$ & Range & S.D. & $\mathbf{N}$ & $\mathrm{x}$ & Range & S.D. & \\
\hline \begin{tabular}{|l} 
Davivongs \\
(1963)
\end{tabular} & 50 & 2.97 & $2.5-3.7$ & 0.229 & 50 & 2.75 & $2.5-3.1$ & 0.148 & $<0.001$ \\
\hline \multicolumn{10}{|l|}{ Flander(1978) } \\
\hline White & 50 & 3.35 & - & 0.332 & 50 & 2.96 & - & 0.182 & $<0.01$ \\
\hline Black & 50 & 3.85 & - & 0.210 & 50 & 2.88 & - & 0.283 & $<0.01$ \\
\hline \begin{tabular}{|l} 
Raju et al \\
$(1980)$
\end{tabular} & 33 & 3.03 & $2.16-3.89$ & 0.288 & 11 & 2.76 & 92.3 .6 & 0.280 & $<0.01$ \\
\hline Bagde (1981) & 56 & 3.24 & $2.8-3.6$ & 0.220 & 25 & 2.84 & $2.4-3.1$ & 0.20 & $<0.001$ \\
\hline $\begin{array}{l}\text { S.S.Dapate } \\
(1997)\end{array}$ & 117 & 3.01 & $2.0-3.06$ & 0.316 & 83 & 2.98 & $2.5-3.7$ & 0.267 & $<0.05$ \\
\hline Mishra (2003) & 74 & 3.00 & $2.6-3.7$ & 0.258 & 42 & 2.93 & $2.4-3.2$ & 0.215 & \\
\hline Kanika(2011) & 40 & 3.15 & $2.4-4.41$ & 0.41 & 10 & 2.85 & $2.6-3.28$ & 0.23 & 0.033 \\
\hline $\begin{array}{l}\text { Jyotinath K et al } \\
(2012)\end{array}$ & 45 & 2.95 & $2.4-3.4$ & 0.22 & 36 & 3.11 & $2.1-4.1$ & 0.42 & 0.0315 \\
\hline Present Study & 146 & 3.07 & $2.27-4.14$ & 0.3275 & 136 & 2.89 & 2.24-3.97 & 0.3275 & $<0.001$ \\
\hline
\end{tabular}

Mean value of index of body of $1^{\text {st }}$ sacral vertebra for male sacra is 64.92 (range $-47.76-97.62$ ) and for female sacra is 65.43 (Range49.28 - 102.68). The demarking point for male sacra is $>92.22$ and for female sacra is $<39.97$. Thus sacrum with index of body of S-1 above 92.22 is definitely male and below 39.97 is definitely female. The mean index of S1 in male and female sacra observed in the present study is similar to that reported in Australian aborigines and in Agra and Punjab regions of India. In Present study, mean values of index of S-1 is much closer to observations of Raju et al (1988), Nisha Y., Joshi UU[15,16] and lower than Jyotinath K (2012) of Telangana region. [Table -6]

Table 6: Comparison of present study with other studies for Index of Body of First Sacral Vertebra (S1)

\begin{tabular}{|c|c|c|c|c|c|c|c|c|c|}
\hline \multirow{2}{*}{$\begin{array}{c}\text { Previous } \\
\text { Researchers }\end{array}$} & \multicolumn{4}{|c|}{ Male } & \multicolumn{4}{|c|}{ Female } & S.S.D. \\
\hline & $\mathbf{N}$ & $\mathrm{x}$ & Range & S.D. & $\mathbf{N}$ & $\mathrm{x}$ & Range & S.D. & $\mathbf{P}$ \\
\hline $\begin{array}{l}\text { Davivongs } \\
\text { (1963) }\end{array}$ & 50 & 63.03 & $54.9-72.5$ & 4.40 & 50 & 62.84 & $54.2-72.2$ & 6.25 & N.S. \\
\hline $\begin{array}{l}\text { Raju et al } \\
(1980)\end{array}$ & 33 & 64.42 & $42.04-88.8$ & 7.48 & 11 & 65.52 & $46.71-84.34$ & 6.27 & N.S. \\
\hline Bagde (1981) & 56 & 63.32 & $52.73-76.09$ & 5.27 & 25 & 62.40 & $54.35-76.0$ & 6.41 & $<0.001$ \\
\hline $\begin{array}{l}\text { S.S.Dapate } \\
(1997)\end{array}$ & 117 & 65.15 & $52.0-86.48$ & 6.901 & 83 & 67.57 & $56.0-84.85$ & 7.684 & $<0.05$ \\
\hline Mishra (2003) & & 61.73 & 56.00-72.09 & 4.07 & & 68.60 & $60.00-76.09$ & 4.92 & \\
\hline $\begin{array}{l}\text { Jyotinath K et al } \\
\text { (2012) }\end{array}$ & 45 & 66.79 & $55-81$ & 7.31 & 36 & 66.79 & $41-86$ & 8.83 & 0.982 \\
\hline $\begin{array}{l}\text { Joshi UU et al } \\
(2016)^{16}\end{array}$ & & 63.58 & $51.38-78.30$ & 4.94 & & 65.29 & $35.3-88.43$ & 7.94 & $>0.05$ \\
\hline Present Study & 146 & 64.92 & $47.76-87.62$ & 7.44 & 136 & 65.43 & $49.28-102.68$ & 7.93 & 0.854 \\
\hline
\end{tabular}

\section{Conclusion}

The present study, concludes with the following selected morphometric measurements of the first sacral vertebra that will be helpful to determine the sex of unknown sacra or the part of sacrum in central india region. 
Table 7

\begin{tabular}{|c|l|c|c|c|c|c|c|}
\hline $\begin{array}{c}\text { S. } \\
\text { No. }\end{array}$ & Parameter $(\mathbf{c m s})$ & Sex & Mean & S.D. & Range & t-value & P-value \\
\hline \multirow{2}{*}{1.} & T.D. of S-1 & $\mathrm{M}$ & 4.78 & 0.5383 & $3.5-6.17$ & 4.8839 & $<0.001$ \\
\cline { 3 - 7 } & & $\mathrm{F}$ & 4.46 & 0.5425 & $3.11-5.59$ & & \\
\hline 2. & A.P. diameter of S-1 & $\mathrm{M}$ & 3.07 & 0.3275 & $2.27-4.14$ & 4.2262 & $<0.001$ \\
\cline { 3 - 7 } & & $\mathrm{F}$ & 2.89 & 0.3275 & $2.24-3.97$ & & \\
\hline \multirow{2}{*}{3.} & Index of S-1 & $\mathrm{M}$ & 64.92 & 8.4429 & $47.76-97.62$ & 0.0568 & 0.8548 \\
\cline { 3 - 6 } & & $\mathrm{F}$ & 65.43 & 8.9327 & $49.28-102.68$ & & \\
\hline
\end{tabular}

After a detailed study and comparison of the present study with other studies, it can be concluded that demarking points and identification point help in sexing the sacrum with much greater accuracy than non-metric methods. The demarking points of transverse and antero-posterior diameter of body of S1 is valid and reliable measured indicator and index of first sacral vertebra is statistically significant for sex determination of unknown sacra. Cluster sampling technique can be applied in study of unknown sacra. Thus, measured indicators of first sacral vertebra can be used for the anatomical and forensic purpose where partial or broken sacra is only skeletal remains.

\section{References}

1. Susan Standring. Gray's Anatomy- The anatomical basis of clinical practice. $40^{\text {th }}$ ed. Churchill Livingstone (London): Elsevier Publishers; 2008, pp.-724-8 and 135960.

2. Krogman W. M. In the Human Skeleton in Forensic medicine. Thomas Springfield (Ellinois);1962.

3. W. Henry Hollinshead, Cornelius Rosse. Text Book of Anatomy. $4^{\text {th }}$ ed. Philadelphia Harper and Row Publishers, 1985:pp. 740.

4. Bagde, K.G. (1981): Determination of sex from axial skeleton M.S. Dissertation-Marathwada University Aurangabad. Cited by Maddikunta.

5. Vinod kumar, Longia, G.S. and Jain, P.N (1984): Anthropometrical study of human sacrum. J.Anat. Soc. India, 33:(1):57.

6. Mishra S. R.,Singh PJ, Agrawal AK, Gupta RN. Identification of sex of sacrum of Agra region. J.Anat.Soc.Ind. 2003;52(2):132-6.

7. Dr. Zarna Patel, Dr. B. Thummar, Dr. S. P. Rathod, Dr. T. C. Singel, Dr. S. Patel, Dr. A Zalawadia. Multicentric morphometrical study of dry human sacrum of Indian population in Gujrat region. NJIRM 2011;Vol.2(2).April - June special:31-5.

8. Raju and Singh P. B. Sex determination and Sacrum. JASI 1980;30(1):pp.13-5.

9. Kanika S, Singla RK, Kalsey G, Sharma G. Role of sacrum in sexual dimorphism - A morphometric study. J. Indian acad. Forensic med. July-sept. 2011, vol33,No3 pp206-10.

10. Maddikunta V, Raviender M.:Morphometric study of sacrum in sex determination in Telangana region people. IJRMS,2014;Feb:2(1):164-74.

11. Nisha Y, kopal S, Kalpana P:Determination of sex using dry adult human sacrum- A morphometric study. IJCRR, vol. 7 issue -3 feb 2015:22-8.
12. Joshi UU, Puranik M : Various sacral indices: role in study of sexual dimorphism. Int. Jr Res Med Sci. 1016 Mar, 4(3):841-6. 